II Congresso Brasileiro de

Fluidodinâmica Computacional

27 a 29 de Junho de 2018

Rio de Janeiro, RJ

\title{
IMPLEMENTAÇÃO DAS EQUAÇÕES DA ENERGIA E CONSERVAÇÃ̃O DE ESPÉCIE QUÍMICA NA ABOR- DAGEM SUPERFICIAL PARA FILMES LÍQUIDOS
}

\author{
R. P. ANJOS, T. S. KLEIN E L. F. L. R. SILVA \\ Universidade Federal do Rio de Janeiro, Escola de Química \\ Email para contato: rodrigopanjos1@hotmail.com
}

\begin{abstract}
RESUMO - Escoamentos anulares se caracterizam pela formação de filme líquido na parede da tubulação. Sua importância é grande, pois ocorre em diversos equipamentos industriais. Nesse sentido, se torna interessante representar esse tipo de escoamento por fluidodinâmica computacional (CFD). O pacote de código livre FOAM-extend possui uma implementação numérica para modelos superficiais que caracteriza o filme líquido isotérmico e para uma substância pura. O objetivo deste trabalho se concentra na implementação das equações de conservação de espécies químicas e energia interna. A implementação foi avaliada para o caso do escoamento do filme líquido em torno de um cilindro. Os resultados mostram que a energia interna e as espécies químicas são corretamente advectadas no domínio estudado, o que valida a implementação.
\end{abstract}

\section{INTRODUÇÃO}

A ocorrência de escoamento anular com formação de filmes líquidos ocorre em algumas situações de interesse na engenharia como trocadores de calor e canais de ebulição (Li e Anglart, 2015).

Devido a essas aplicações, é importante o desenvolvimento de uma metodologia robusta, capaz de representar os efeitos físicos desse tipo de escoamento em simulações por fluidodinâmica computacional (CFD). Para tal, o pacote CFD de código livre FOAMextend 4.0 foi usado neste trabalho com o objetivo de implementar as equações de conservação de energia interna e conservação de espécies químicas ao código do liquidFilmFoam, originalmente aplicado para a simulação bidimensional de filmes líquidos com substância pura e isotérmicos.

\section{MODELAGEM}

As equações empregadas para simulação do filme líquido são baseadas na abordagem de Li e Anglart (2015). Neste trabalho, considera-se que a espessura do filme é muito pequena, o que permite desconsiderar o escoamento na direção normal à parede e assumir que os gradientes normais a ela são muito maiores que os tangenciais. A partir disso, as equações de conservação podem ser integradas na direção normal à parede, tornandoas bidimensionais em termos de variáveis médias. A Equação 1 apresenta a equação da 


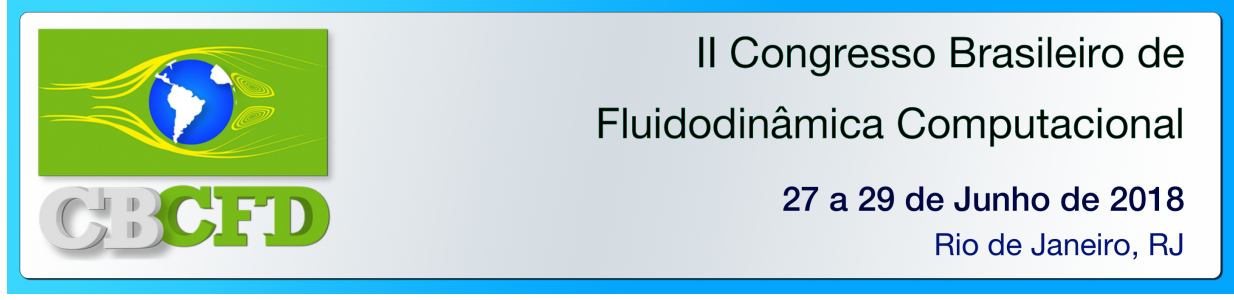

continuidade para o filme líquido e a Equação 2 mostra a equação de conservação de momento linear:

$$
\begin{gathered}
\frac{\partial h}{\partial t}+\boldsymbol{\nabla} \cdot\left(h \mathbf{u}_{\mathbf{f}}\right)=0, \\
\frac{\partial h \mathbf{u}_{\mathbf{f}}}{\partial t}+\boldsymbol{\nabla} \cdot\left(h \mathbf{u}_{\mathbf{f}} \mathbf{u}_{\mathbf{f}}\right)=\mathbf{G}_{\mathbf{s}} h-h \boldsymbol{\nabla} p_{s},
\end{gathered}
$$

em que $h$ é a altura do filme, $\mathbf{u}_{\mathbf{f}}$ a velocidade do líquido no filme, $\mathbf{G}_{\mathbf{s}}$ é o termo gravitacional e $p_{s}$ é a pressão no filme.

Vale notar que existe a adição do termo fonte relativo a efeitos gravitacionais, o qual também é mostrado por Li e Anglart (2015). Ademais, são desconsiderados os termos difusivos e não estão implementados outros termos fontes normalmente relacionados a alguns fenômenos comuns no escoamento anular de filmes líquidos: forças de tensão superficial, arraste/deposição, escoamento secundário no gás e ondas (Butterworth, 1972).

Neste trabalho, foram implementadas as equações de conservação de energia interna e espécies químicas Hauke (2006), com a aplicação da metodologia para modelos de filme mostrada por Li e Anglart (2015):

$$
\begin{gathered}
\frac{\partial h e}{\partial t}+\nabla \cdot\left(h e \mathbf{u}_{\mathbf{f}}\right)=0 \\
\frac{\partial h y_{A}}{\partial t}+\boldsymbol{\nabla} \cdot\left(h y_{A} \mathbf{u}_{\mathbf{f}}\right)=0,
\end{gathered}
$$

em que $e$ é a energia interna específica e $y_{A}$ é fração molar de um dado componente no filme.

Para os fins deste trabalho, só foi considerada a parte advectiva nas equações implementadas, negligenciados os efeitos difusivos e termos fonte, pois o intuito é avaliar a possibilidade de implementação dessas equações, não fornecer a modelagem adequada para um dado caso de interesse.

\section{METODOLOGIA}

Na metodologia, as Equações 3 e 4 foram adicionadas ao código liquidFilmFoam do programa FOAM-extend 4.0, o qual possui implementadas como padrão as Equações $1 \mathrm{e}$ 2. A Equação 3 é adicionada de forma similar às duas padrão, em que é necessário um arquivo de inicialização, tal qual para velocidade e pressão. No que tange aos diferentes componentes previstos pelo código, foi feito um dicionário de espécies, no qual elas são listadas juntas a sua massa molecular e número de moles. Ademais, a última espécie listada nesse dicionário não tem sua fração molar calculada via equação de transporte (Equação 4), ela é considerada como a espécie limitante, ou seja, sua fração molar é dada pela unidade subtraída do somatório das frações das demais espécies. Também é necessário um arquivo de inicialização para fração molar de todas as espécies declaradas.

Como o filme líquido é considerado muito fino, a altura dele é obtida a partir da Equação 1, porém as outras propriedades são calculadas somente em um plano normal ao filme e consideradas constantes ao longo de sua altura, uma vez que são variáveis médias nessa direção após a integração. 


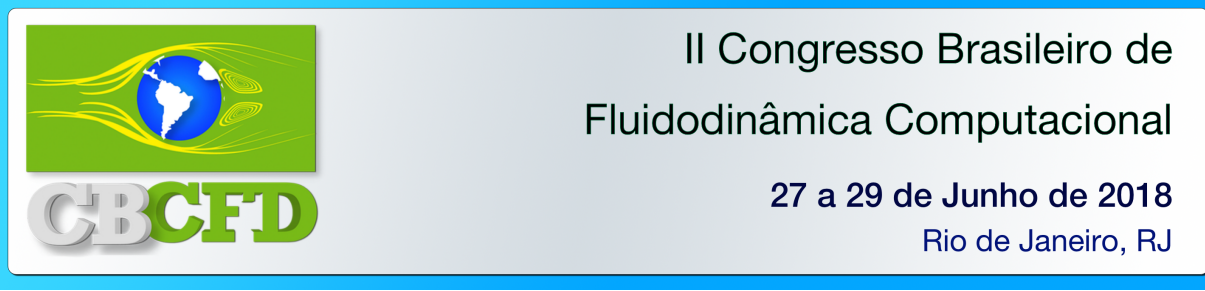

Para verificar se a implementação foi bem sucedida, as modificações foram testadas no tutorial cylinder do próprio programa. Esse caso consiste em um escoamento transversal a um cilindro, com formação de um filme líquido na superfície externa do mesmo, que tem 8, $0 \mathrm{~mm}$ de raio. O escoamento acontece em um plano inclinado, com gravidade igual a $4,9 \mathrm{~m} . \mathrm{s}^{-2}$ na direção do escoamento, $-8,5 \mathrm{~m} . \mathrm{s}^{-2}$ na direção em que o filme é formado e $0,0 \mathrm{~m} \cdot \mathrm{s}^{-2}$ na terceira direção.

O domínio é inicializado com valor uniforme e igual a 0,41 mm de espessura de filme, velocidade nula, energia interna nula e concentrações molares de 0,00, 0,00 e 1,00 para o $\mathrm{N}_{2}, \mathrm{O}_{2}$ e $\mathrm{CH}_{4}$ respectivamente. De modo a testar a advecção da energia interna e composição das espécies químicas, a corrente de entrada é especificada com $80 \mathrm{~J} . \mathrm{Kg}^{-1}$ de energia interna e concentrações molares de 0,80, 0,20 e 0,00 para o $\mathrm{N}_{2}, \mathrm{O}_{2}$ e $\mathrm{CH}_{4}$ respectivamente. Foi especificado gradiente nulo para a velocidade na entrada e saída.

No que tange aos métodos numéricos, foram mantidas as configurações padrão do tutorial: simulação transiente com discretização dos termos temporais reallizada com método de Euler e passo de tempo de 0,0002 s; os divergentes foram discretizados com o método Gamma, exceto o de velocidade, no qual foi empregado o método upwind de segunda ordem; os resíduos foram ajustados para $1,0 * 10^{-7}$.

\section{RESULTADOS}

A Figura 1 mostra o plano em que as equações bidimensionais apresentadas anteriormente são resolvidas, preenchido pelos valores de energia interna no instante $t=0,4 \mathrm{~s}$. Percebe-se que a energia interna é corretamente advectada ao longo do domínio de estudo, de acordo com escoamento transversal a um cilindro. Sendo assim, a implementação da equação da energia foi exitosa.

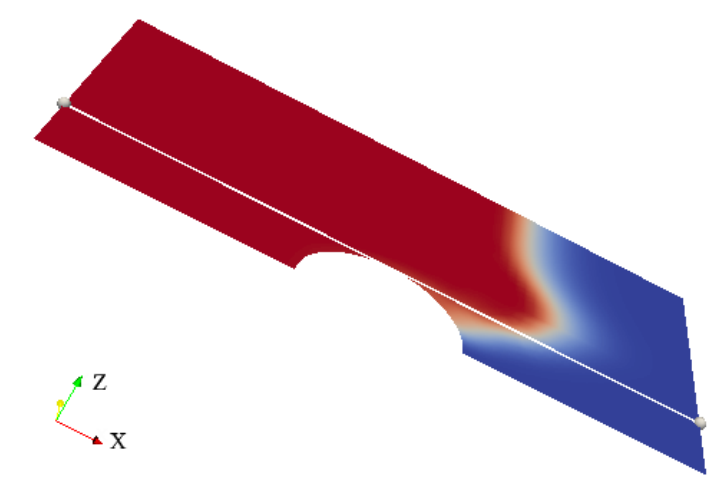

Energia interna $(\mathrm{J} / \mathrm{Kg})$

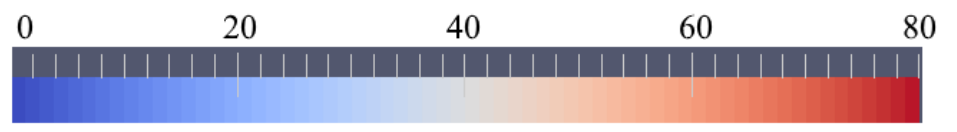

Figura 1 - Perfil de energia interna no plano em que as equações são resolvidas. 


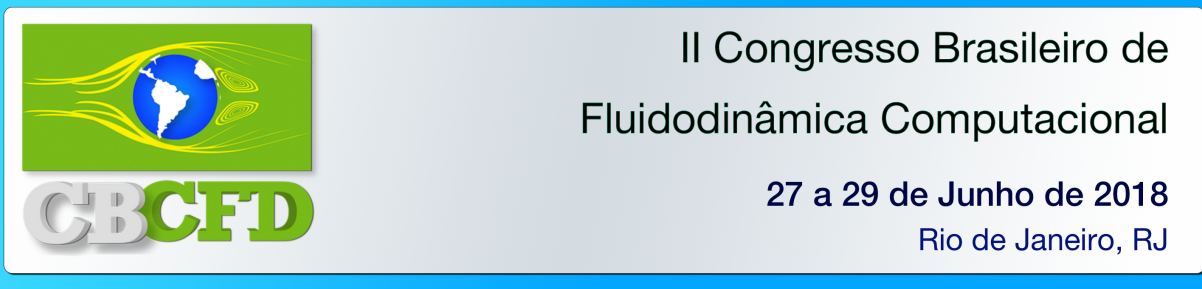

A Figura 2 mostra o perfil de concentração das espécies químicas na linha indicada na Figura 1 também em $t=0,4 \mathrm{~s}$. Pode-se ver que os componentes $\mathrm{N}_{2}$ e $\mathrm{O}_{2}$ são advectados a partir da entrada para o interior do domínio, à medida que o $\mathrm{CH}_{4}$ está saindo do mesmo ao longo do tempo, ou seja, os três se comportam conforme o esperado. Ademais, observa-se que o somatório das frações molares retorna $1 \mathrm{em}$ todos os pontos da linha analisada. Com tais características, é possível afirmar que a implementaçáo das equações de conservação por componente foi bem sucedida.

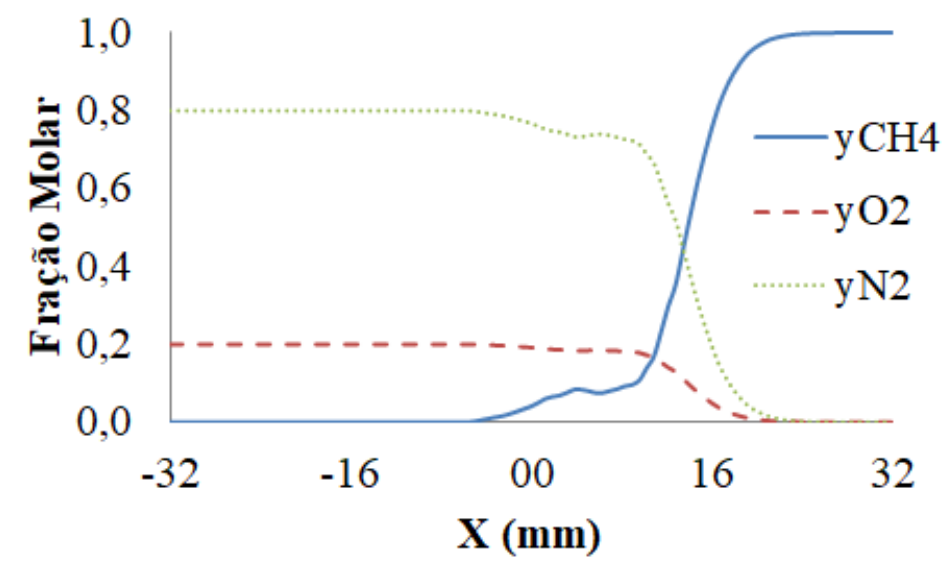

Figura 2 - Fração molar dos componentes $\mathrm{N}_{2}, \mathrm{O}_{2}$ e $\mathrm{CH}_{4}$ na linha destacada na Figura 1.

\section{CONCLUSÃO}

A implementação da equação da energia e das equações de conservação de massa por componente no código liquidFilmFoam do FOAM-extend foi realizada com sucesso.

\section{AGRADECIMENTOS}

Os autores agradecem ao CNPq, Conselho Nacional de Desenvolvimento Científico e Tecnológico, pela bolsa de doutorado concedida a Rodrigo Petrone dos Anjos.

\section{REFERÊNCIAS}

Butterworth, D. Air-water annular flow in a horizontal tube. Progress in Heat and Mass Transfer, 6, 415-424, 1972.

Hauke, G. An Introduction to Fluid Mechanics and Transport Phenomena. Springer, 2006.

Li, H.; Anglart, H. CFD model of diabatic annular two-phase flow using the eulerian-lagrangian approach. Annals of Nuclear Energy, 77, 415 - 424, 2015. 